\title{
Una historia peligrosa: la Historia Reciente bajo sospecha ${ }^{1}$
}

\author{
Héctor Altamirano* \\ Universidad de la República
}

\begin{abstract}
Resumen
Desde el principio hay que aclarar que el trabajo no pretende cerrar un tema, sino simplemente presentar algunas dudas, algunas interrogantes a un objeto de estudio (la historia reciente) que desde la asunción al gobierno del Frente Amplio en marzo de 2005 ha cobrado nuevo impulso a nivel de la sociedad y por tanto a nivel de la academia.

Previamente a trabajar sobre el tema de la historia reciente, se hará una recorrida por algunas concepciones que nos aproximarán a lo qué es la ciencia; qué se entiende por ella; y a la relación que existe entre la ciencia y la sociedad; entre la ciencia y la política. Al decir de Bourdieu se reflexionará sobre lo simbólico y las luchas entre las diferentes fuerzas que pugnan por imponer su mirada.

Luego se pasará a trabajar el tema de la historia reciente en el Uruguay. Allí el trabajo tendrá algunas preguntas guías. Estas preguntas serán las siguientes: $¿$ el conocimiento del pasado reciente está limitado por problemas o cuestiones sociales (económicos, políticos, miedos, etc.)?; ¿el discurso sobre la historia reciente de algunos sectores políticos está más presente en la sociedad que los discursos producidos por los cientistas sociales?; ¿qué papel juegan estos científicos en torno a la vida presente del país y a la memoria colectiva de nuestra sociedad?

A través de estas preguntas se intentará reflexionar, desnaturalizar y problematizar la producción historiográfica sobre el pasado reciente de nuestro país y en cómo se vinculan estos temas con el presente.
\end{abstract}

\section{Palabras claves}

Ciencia, historia reciente, luchas simbólicas

\begin{abstract}
First of all it must be clarified that this work does not intend to close an issue, but simply to present some questions, some grey areas about an object of study (recent history) which has acquired new momentum in society and therefore in academia, since the Frente Amplio
\end{abstract}

\footnotetext{
${ }^{1}$ Una primera versión de este texto fue presentado en las IV Jornadas de Historia Política, Mesa Historiografías, organizado por Área de Historia Política, Instituto de Ciencia Política, Facultad de Ciencias Sociales, Universidad de la República, Montevideo, Uruguay, 8, 9, 10 de julio de 2013. Quiero agradecer a los evaluadores anónimos de la Revista Páginas las sugerencias planteadas. * Estudiante de la Maestría en Ciencias Humanas, Opción Estudios Latinoamericanos, Facultad de Humanidades y Ciencias de la Educación, Universidad de la República, Uruguay
}

Esta obra está sujeta a la Licencia Reconocimiento-NoComercial-Compartirlgual 4.0 Internacional de Creative Commons. http://creativecommons.org/licenses/by-nc-sa/4.0/ 


\section{Una historia peligrosa: la Historia Reciente bajo sospecha}

took office in the government in March 2005.

Before working on the subject of recent history, we will revisit some concepts to offer an approximation to what is science, what is meant by it, and the relationship between science and society and between science and politics. In the words of Bourdieu, we will reflect on the symbolic and on the struggles between the different forces that attempt to impose their views.

Then we will start the work on the issue of recent history in Uruguay. For that purpose, our work will have some guiding questions. These questions are as follows: Is the knowledge of the recent past limited by problems or social issues (whether economic or political, or fears, etc.); is the discourse about the recent history of some political sectors more present in society that the discourses produced by social scientists?; what role do these scientists play around the present life of the country and the collective memory of our society?

Through these questions, we will try to reflect on, denaturalize and problematize the historiographical production about the recent past of our country and about how these issues relate to the present.

\section{Keywords}

Science, recent history, symbolic struggles 


\section{Héctor Altamirano}

\section{La historia reciente en Uruguay.}

En estos últimos años (2003 a la fecha) ha existido un verdadero auge con respecto al estudio de la historia reciente en Uruguay o para ser más precisos a la última dictadura cívico-militar.

En esta parte del trabajo lo que haremos es presentar algunos de los trabajos que se desarrollaron estos años y cuáles fueron o cuáles son las dificultades que, a nuestro modesto entender pueden tener los investigadores que están estudiando este tema.

Las preguntas que de alguna manera guiaron el trabajo y fueron el impulso del mismo fueron las siguientes:

1. ¿el conocimiento del pasado reciente está limitado por problemas o cuestiones sociales (económicos, políticos, miedos, etc)?

2. ¿el discurso sobre la historia reciente de algunos sectores políticos está más presente en la sociedad que los discursos de la academia y de los científicos?

3. ¿qué papel juegan los científicos en torno a la vida presente del país y a la memoria colectiva de nuestra sociedad?

Una de las obras que aparecieron en estos años fue El presente de la dictadura. Estudios y reflexiones a 30 años del golpe de Estado en Uruguay (Marchesi, A. Markarián, V. Rico, A. Yaffé, J (comp.), 2004). La obra reúne ponencias y presentaciones realizadas a 30 años del golpe de estado en una actividad que los mismos compiladores explicitan que movilizó a muchos investigadores y a la sociedad en general.

Algo que nos llama la atención es la fecha en la que se editó este material: octubre de 2004. Es interesante recordar y apuntar que el 2004 fue año electoral y que justamente en el mes que se edita el libro fueron las elecciones nacionales, las que manifestarían un cambio histórico para el país: ni el Partido Colorado, ni el Partido Nacional estarían en el gobierno, asumiría por primera vez la coalición Frente Amplio². Justamente esta coalición es la que más réditos políticos puede lograr con la explosión de los estudios de la historia reciente pues, en sus filas hay grupos políticos, partidos y personalidades que fueron brutalmente reprimidos y prohibidos durante la dictadura. Ya en el pasaje a la democracia, va a levantar las banderas de las organizaciones de Derechos Humanos, especialmente la de Madres de Detenidos y Desaparecidos ${ }^{3}$.

\section{2. ¿Relación entre ciencia y política?}

En dicha obra encontramos un artículo de Carlos Demasi titulado Un repaso a la teoría de los dos demonios. En dicho artículo se dice que esa teoría "es una

\footnotetext{
2 Para profundizar en la historia de esta coalición de partidos y sus cambios históricos que lo lleva a pasar de ser un partido de izquierda a uno de centro-izquierda, ver Yaffé (2005)

${ }^{3}$ En otro apartado profundizaremos al respecto.
} 


\section{Una historia peligrosa: la Historia Reciente bajo sospecha}

explicación ya clásica del quiebre de las instituciones. Según se señala, la sociedad fue víctima del embate de dos fuerzas antagónicas, la guerrilla y el poder militar; y en el contexto de esa lucha, el golpe fue un resultado inevitable" (Demasi, 2004: 67). En este momento no analizaremos el artículo (aunque lo consideramos de sumo interés), pero algo a lo que nos referiremos es a que, en este trabajo, se nombra y se apunta a Julio María Sanguinetti ${ }^{4}$ en varias oportunidades, pues se lo considera como uno de los mayores responsables, uno de los artífices, de que esta teoría se encuentre instituida como una verdad o como sentido común en la opinión pública, en buena parte de la academia, en variados sectores y dirigentes políticos (de una u otra forma hoy todos los partidos con representación parlamentaria tienen en sus filas sectores que concuerdan con esta teoría). Recordemos que J. M. Sanguinetti era en ese 2004 un activo político del Partido Colorado que se presentaba para la Cámara de Senadores.

Ahora bien, ¿no está jugando un rol político el investigador al encarar este tema?, ¿no está influyendo en la ciudadanía, para que observaran a Sanguinetti con ojos de desconfianza?, ¿no se puede pensar que en los investigadores existen intereses políticos?

Este es uno de los problemas que percibimos pueden existir para deslegitimar socialmente el estudio de la historia reciente. Muchas veces se puede ver en la prensa escrita, o escuchar en diversos medios de comunicación masivos, un ataque y si se quiere un profundo resquemor, por parte de múltiples políticos profesionales (tanto del Partido Nacional como del Partido Colorado, como del Frente Amplio) y de las Fuerzas Armadas a la idea de revisar la lo sucedido en la dictadura y en la posdictadura.

¿Qué es lo que alienta este nerviosismo?, ¿no se demuestra con este nerviosismo una relación entre política y ciencia?

En el año 2005 con la asunción del nuevo gobierno (Frente Amplio) se profundiza la

\footnotetext{
4 Político perteneciente al Partido Colorado. Fue dos veces Presidente del Uruguay (1985-1990 y 1995-2000). Como se plantea en el artículo citado, fue durante los "años de plomo", un protagonista de ese tiempo. Es recordado por su participación en el gobierno del dictador Juan María Bordaberry como impulsor de la Ley de Educación que llevó al control y la represión de las instituciones educativas del país. Al respecto de Giorgi plantea lo siguiente: “...no se puede considerar aisladamente [el] desempeño político de [J. M. Sangüinetti] de los últimos años sin incorporar una mirada de más larga duración. En efecto, si se contemplan las tres últimas décadas de la vida política del Uruguay, es decir desde 1985 hasta 2014, un tercio de ella -entre 1985-1990 y 1995-2000- fue gobernada directamente por Sangüinetti. Y si se suma a eso que el Foro Batllista fue el sector de mayor incidencia -ya que fue el más votado dentro del Partido Colorado- en el gabinete de Jorge Batlle durante el período de gobierno 2000-2005, son 15 años de incidencia política directa, nada menos que la mitad de los últimos treinta años. Por cierto que habría que agregar también su relevancia en el lapso transcurrido entre 1980-1984, en el que jugó un papel clave al interior del bloque opositor democrático en el diseño y conducción del tipo de transición pactada con los militares que resultó finalmente adoptada en Uruguay para el retorno de la democracia". (de GIORGI, 2014: 11). Se hace necesario aclarar que este político en las últimas elecciones no se presentó como candidato y estuvo bastante alejado del frente de batalla. Su partido en las últimas elecciones ha sufrido una dura caída de votantes y esto lo llevó a perder gobiernos departamentales y a estar hoy en una crisis interna durísima.
} 


\section{Héctor Altamirano}

explosión del estudio sobre la historia reciente. Es este gobierno en la figura del Presidente electo Tabaré Vázquez que "encomienda" el 30 de mayo del mismo año a José Pedro Barrán, Álvaro Rico y Gerardo Caetano a realizar una investigación sobre lo sucedido durante la última dictadura cívico-militar en torno a los detenidosdesaparecidos y los niños secuestrados durante la dictadura (Caetano, 2008: 165166). Esta investigación se realizó con una reinterpretación de la denominada "Ley de impunidad"5. En el artículo $4^{0}$ de dicha ley se establece lo siguiente:

Sin perjuicio de lo dispuesto en los artículos precedentes el Juez de la causa remitirá al Poder Ejecutivo testimonios de las denuncias presentadas hasta la fecha de promulgación de la presente ley referentes a actuaciones relativas a personas presuntamente detenidas en operaciones militares o policiales y desaparecidas así como de menores presuntamente secuestrados en similares condiciones. El Poder Ejecutivo dispondrá de inmediato las investigaciones destinadas al esclarecimiento de estos hechos. El Poder Ejecutivo dentro del plazo de ciento veinte días a contar de la comunicación judicial de la denuncia dará cuenta a los denunciantes del resultado de estas investigaciones y pondrá en su conocimiento la información recabada.

Hasta ese momento el Poder Ejecutivo no había llevado adelante ninguna investigación al respecto. En junio de 2007 se hace público la investigación encomendada por Tabaré Vázquez. Es así que se publican 5 tomos bajo el título "Investigación histórica sobre Detenidos-Desaparecidos. En cumplimiento del Artículo 4ํ de la Ley 15.848". Son 3.632 páginas en las que se avanza sobre lo sucedido en la dictadura. Como dice uno de los coordinadores de dicha investigación el trabajo buscó ser "básicamente descriptivo" y no desarrollar "interpretaciones sobre el período analizado" (Caetano, 2011: 166).

Otro momento caliente ocurrió con la decisión del CO.DI.CEN 6 (órgano máximo de la Enseñanza Primaria y Secundaria en Uruguay) de brindar cursos de actualización a los maestros y profesores sobre los últimos cincuenta años de la historia mundial, regional y local. Obviamente que aquí nuevamente estalló una discusión mediática a través de los representantes de la oposición al gobierno del Frente Amplio, en donde se reafirmaba la idea acerca que establecía que el nuevo gobierno quería "lavar la cabeza" de los jóvenes y quería imponer una "historia oficial". Para contrarrestar estas posiciones en la presentación del material el Vicepresidente del CODICEN José Pedro Barrán decía lo siguiente: "el CODICEN no pretende que [esta] Historia (...) sea la "historia oficial" ni una exposición sobre la "verdad".

Sin dudas que un punto álgido de esta relación se vivió cuando uno de los integrantes del grupo de investigadores (Carlos Demasi) fue hostigado por el

\footnotetext{
${ }^{5}$ Ley № 15.848 votada el 23 de diciembre de 1986 plantea la Caducidad de la Pretensión Punitiva del Estado. Sobre esta ley y lo que implicó e implica aun hoy, nos detendremos más adelante en este trabajo.

${ }^{6}$ Consejo Directivo Central
} 


\section{Una historia peligrosa: la Historia Reciente bajo sospecha}

Partido Nacional. El hecho en concreto hace referencia a una lectura, a una interpretación que ha construido dicho investigador, con la cual este partido no estaba de acuerdo 7 .

A partir de estas decisiones del Frente Amplio se gestó la disputa, la lucha por controlar la memoria, la lucha por controlar el pasado y de esa manera controlar el presente: allí se da la lucha entre dos productores simbólicos que pretenden actuar sobre la sociedad cada uno desde su lógica, aunque en un mismo campo.

A partir del ataque de los opositores ${ }^{8}$ a que el gobierno llevara esta "revisión histórica", es que se publica en el año 2008 el libro: "Historia reciente; historia en discusión"9 coordinado por Álvaro Rico, en donde varios de los investigadores que formaron parte de la "Investigación histórica sobre Detenidos-Desaparecidos. En cumplimiento del Artículo 4ํㅜ de la Ley 15.848" y de los investigadores que tuvieron a su cargo la los cursos de actualización llevados adelante por mandato del CODICEN, ensayaron una réplica o explicación-fundamentación de su trabajo con respecto al estudio de esta temática ${ }^{10}$.

En cierta forma el problema con el que se encuentran los investigadores -en este caso- es el de la legitimidad, legitimidad que se ve amenazada por un actor, por un productor de sentido que se encuentra en el mismo campo que el investigador: el social.

Es clave tener en cuenta que "el poder simbólico hace ver y hace creer, confirma o transforma la visión del mundo y, por ello la acción sobre el mundo, por lo tanto el mundo" (Bourdieu, 2009: 71-72). La disputa está en ese punto: la posibilidad de alterar-simbólicamente- el orden establecido, pues "un discurso [que rompe con lo hegemónico] encierra un poder simbólico de movilización y de subversión, poder de actualizar el poder potencial de las clases dominadas" (Bourdieu, 2009: 72).

Debemos aclarar que estas relaciones entre ciencia y política, no nos parecen algo negativo. El problema creemos que surge a la hora de pensar en los científicos-

\footnotetext{
7 Para este trabajo no creemos adecuado detenernos en los aspectos específicos del caso, sólo queremos trabajar este punto para presentar la problemática del estudio de estos temas.

${ }^{8}$ Dichos ataques fueron expresados y/o amplificados por los medios de prensa, especialmente el diario El país y el Semanario Búsqueda.

${ }^{9}$ Como dice en la presentación el antecedente de "Este libro es el Seminario universitario del mismo nombre, realizado el jueves 14 y 15 de diciembre del año 2006 en el Salón Rojo del Centro de Conferencias de la Intendencia Municipal de Montevideo (IMM) y en la Sala de la Dirección Nacional de Impresiones y Publicaciones Oficiales (IMPO)" y tuvo el auspicio de la Dirección de Derechos Humanos del Ministerio de Educación y Cultura (MEC) y con el apoyo del Programa de las Naciones unidas para el Desarrollo (PNUD)

${ }^{10}$ Los títulos de varios de los trabajos publicados en dicha obra lo dejan ver: "Los cuestionamientos y desafíos de la historia reciente" de J.P. Baarrán; "Combates por la "Historia reciente" en Uruguay" de A. Frega; "2006: el año de historia reciente" de C. Demasi. También en el artículo de G. Caetano podemos encontrar que el académico mencionado ensaya una suerte de defensa de su accionar en este proceso conflictivo, así dice que "Se nos ha agraviado a quienes asumimos la tarea de trabajar en una investigación que buscara un mayor esclarecimiento, tanto postergado, del destino de los desaparecidos y de los niños secuestrados durante la dictadura, adjudicándonos -antes siquiera de leer un renglón del estudio a publicarse- el calificativo de "historiadores oficiales". Nada más lejano a la verdad (...)" (Caetano: 165).
} 


\section{Héctor Altamirano}

investigadores (a los científicos de todas las disciplinas, no solamente las sociales), a los cuales se los percibe -desde la sociedad- como ajenos a las actividades políticas. Aunque también habría que pensar que muchas veces los académicos se colocan en un lugar alejado para no identificarse tan claramente con las disputas sociales del momento.

Todas estas son dudas que surgen nos parece, porque este es un tema sumamente delicado para buena parte de la ciudadanía. Recordemos que este tema recorre el sufrimiento y los momentos más duros de muchas personas. Y si tomamos a la sociedad en su conjunto, hay especialistas que plantean lo siguiente: la represión política vivida en aquellos años creó un quiebre, una fractura en la memoria colectiva de la sociedad, la cual tendrá por mucho tiempo ese corte emocional.

Los investigadores que estudian estos temas plantean que esto se puede percibir en que muchas personas no pueden recordar prácticamente nada de aquellos años, pasan y siguen de largo ante una pregunta que interroga sobre esa parte de la vida, sobre ese período histórico, pues esos recuerdos hacen reaparecer sensaciones y momentos insostenibles o que no son para nada agradables.

Además de lo anterior podemos compartir la siguiente afirmación de Frega: "Es indudable que todo discurso histórico, aún aquél construido con el mayor rigor metodológico y la mayor diversidad de fuentes disponibles en el momento de su elaboración es susceptible de usos políticos" (Frega, 2008: 23).

En los trabajos que citamos anteriormente se pueden percibir muchos de los problemas que existen a nivel del estudio de la historia reciente del Uruguay. Por ejemplo, podemos pensar desde la misma palabra de historia reciente. Esta palabra seguramente permanezca en la academia y pase a través de las distintas etapas escolares con esa denominación. Desde ese momento podemos percibir un problema: qué es lo que se quiere o se pretende estudiar; cuáles son los límites temporales de estos estudios.

Una de las dificultades mayores, uno de los problemas que se tienen y deben superar, es el que hace referencia a los archivos del estado.

Con respecto a este punto podemos agregar que, nuevamente en este sitio se cruzan la ciencia y la política, pues es una voluntad política la que puede permitir acceder a dichos archivos. Se necesitaría una voluntad expresa y real desde los organismos estatales para acceder a dicha información. Al respecto plantean los especialistas que en torno a este tema existen mitos o ideas elaboradas en el imaginario colectivo que harían pensar que teniendo la posibilidad de acceder a estos archivos ya sería suficiente para conocer lo sucedido durante la dictadura.

Referido a este tema que es por demás interesante y a la vez importante, vamos a referirnos a varios artículos que aparecieron en el semanario Brecha, que nos pueden acercar algunos elementos para pensar el tema. En una de estas notas a las que hacíamos referencia aparece la dificultad que existe en el Uruguay en este momento para acceder a la información.

Con respecto a los antes mencionados archivos del terror. Toda la búsqueda que está realizando el gobierno parece que tiene variadas perspectivas, se puede 


\section{Una historia peligrosa: la Historia Reciente bajo sospecha}

percibir este tema de diversas maneras. Sobre todo si pensamos que los investigadores que están estudiando el tema, ellos mismos, ven ese recorte como una dificultad para seguir avanzando en el conocimiento de ese período.

Como dice el periodista Marcelo Pereira "aquí no está en juego sólo el derecho de los familiares de las víctimas, sino también el de la sociedad en su conjunto a conocer su historia"; luego agrega lo siguiente: "y no sólo la posibilidad de establecer autorías, móviles y complicidades en el área de las responsabilidades penales, sino también, en el terreno de las responsabilidades políticas". Finalmente remata la idea planteando que "se trata (en definitiva) sobre que el pasado constituye, sin duda, un poderoso factor ideológico en la lucha por la hegemonía actual y futura. En ese contexto, el poder ejecutivo juega cartas por debajo de la mesa, sin enunciar que se propone..." (Pereira, 2005: 3).

La idea de que la historia es un arma ideológica/política estaría derribando, nuevamente, la imagen vulgarizada que se tiene sobre la ciencia. Pero tampoco seamos ingenuos, esta idea se encuentra presente en la sociedad, a distintos niveles y en distintos ámbitos.

Entonces podemos decir que ¿los historiadores están siendo limitados por el Estado en sus investigaciones? Este es creemos, un gran problema que se les presenta a los científicos-investigadores, pues deben realizar un trabajo fenomenal para poder reconstruir algunos sucesos de nuestro pasado reciente.

Pero en esta intriga de archivos secretos (por voluntad política, "para tener un proceso controlado") aparece o puede presentarse otro problema de la ciencia.

\section{El péndulo y las contradicciones internas}

En este último gobierno encabezado por el mediático Presidente José Mujica (2009-2014) la idea de "mirar al pasado" como algo negativo volvió a circular de forma insistente por la sociedad. No solamente se plantea desde variadas tiendas políticas que esta temática entorpece el desarrollo del país, pues no deja "concentrarse" en lo que realmente importa o que los que miran al pasado "están llenos de odio"; sino que además se retomó la "teoría de los dos demonios" (aquélla impulsada por el ex Presidente J.M. Sangüinetti), de forma abierta y clara.

El discurso del presidente José Mujica del día 18 de mayo de 2011 es un claro ejemplo11. En ese discurso se puede leer lo siguiente: "no podemos trasladarle a las nuevas generaciones de militares las frustraciones de la nuestra, porque necesitamos un país convivible, un país que antes que nada y por encima de sus diferencias tenga el coraje de poner adelante el "nosotros"; luego agregaba que debemos "cultivar una tolerancia superior entre nosotros" y todo esto lo dice no

\footnotetext{
${ }^{11}$ Este es el día que se conmemora el Día del Ejército y la Batalla de Las Piedras (batalla que pertenece al ciclo independentista iniciado en 1810 en el Río de la Plata), ese fue el marco en el que dio el discurso el Presidente J. Mujica.
} 


\section{Héctor Altamirano}

como presidente sino "como viejo que se puso un arma al cinto"12.

En cierta medida la posición que toma el Presidente J. Mujica respecto a este tema y muchos de sus allegados, estarían entorpeciendo y dificultando los avances en esta temática, pues evidencian que el problema fue el enfrentamiento de dos grupos de la sociedad.

Volviendo al tema de la necesidad de conocer los archivos oficiales hay que decir que, pese a no poder ser investigados los archivos públicos del estado, se han podido realizar investigaciones sobre el tema que nos convoca ${ }^{13}$.

Pese a lo antes mencionado, en este momento están superados los conflictos que hacían creer que los documentos solamente eran aquellos que emanaban de las oficinas estatales con un sello que los certificara (se superó la huella positivista) y eso era lo que se aceptaba para reconstruir el pasado.

Hoy se toma como fuente una variedad enorme de dispositivos. Como lo explicaba el propio Rico hace ya un buen tiempo: "esta historia reciente como "asunto de todos", propone "democratizar la producción historiográfica" en sus fuentes tradicionales y conclusiones académicas y, por otro lado obliga a romper la pereza del historiador de "atenerse a lo vivido", a su "diálogo" silencioso y sin respuesta con el documento escrito. La historia reciente es historia de voces que hay que salir a buscar" (Rico, 1989: 46). Reiteramos que en definitiva esto ha permitido hasta el momento, reconstruir buena parte de la historia reciente que conocemos.

En este punto encontramos otro problema para este campo de estudio. Muchas voces no dicen nada o muchas voces dicen algo hoy y mañana dicen otra cosa. ¿Cómo hace el investigador para hacer hablar a aquello a lo que no puede acceder?, ¿cuánto se pierde la sociedad por esta decisión del Estado de no buscar y hacer lo posible para que esos archivos se hagan públicos?, ¿no puede ser esto un elemento que lleva a la sociedad a mirar con recelo esta narrativas del pasado?

\footnotetext{
12 La posición de ex guerrillero, la posición de su pasado "heroico", el culto al héroe guerrero, lo enviste de legitimidad (y deslegitima a todos aquellos que no lo fueron) a su discurso a su decir y a su posición. ¿Qué mensaje queda en la sociedad luego de este tipo de discursos?; ¿sólo los "protagonistas" pueden hablar de esta época?; ¿sólo los "protagonistas" se arrogan el derecho de fosilizar la historia de una sociedad en sus experiencias personales?

13 Los mismos investigadores explicitan que "la documentación revisada por el equipo de investigación fue aquella explícitamente autorizada por el Poder Ejecutivo y la Presidencia de la República, principalmente la que recopiló la Comisión para la Paz en sus labores de investigación y que hoy se encuentra custodiada por la Secretaría de Seguimiento de la COMOPAZ. Asimismo, se trabajó con la documentación que se encuentra organizada en los Archivos del Ministerio de Relaciones Exteriores, Ministerio del Interior, Dirección Nacional de Información e Inteligencia”. Y agrega: "En todo caso, lo novedoso de la presente investigación lo constituye el hecho de que la misma se apoya, fundamentalmente, en la documentación producida por el propio Estado. Somos conscientes como investigadores que hemos utilizado un privilegio que el gobierno actual nos concedió". (Investigación Histórica, 2007: 32). Como se puede leer, en esta investigación no se logró acceder a los archivos de ninguna de las tres armas de las Fuerzas Armadas: Ejército, Marina, Aérea. Sí se llegó a investigar "los repositorios documentales de Inteligencia policial, incluidas las copias de los documentos de Inteligencia militar...”. Es evidente que no se logró acceder a los documentos originales de las Fuerzas Armadas (con la centralidad que éstas tuvieron en aquéllos años) y esto lleva a los mismos investigadores a tener precaución con lo obtenido pues este es "un período caracterizado por secretos, prohibiciones, impunidad" (34).
} 


\section{Una historia peligrosa: la Historia Reciente bajo sospecha}

\section{¿La Nación vs la verdad?}

En la última pregunta creemos que el problema es el de la memoria en relación a la historia con referencia de acontecimientos traumáticos para la sociedad. Y por qué no decirlo para la historia del país.

Una hipótesis que se puede manejar es que para el relato de la historia nacional este es un escollo muy difícil de sortear. Siempre en las historias nacionales se expresa que todos los habitantes de una nación mantienen un lazo, mantienen una unión. Entonces en el imaginario social está presente la idea de que los "uruguayos" formamos una gran familia. Aunque existen posiciones y lecturas que afirman que el Estado-Nación está en crisis o lisa y llanamente que ha dejado de tener presencia a nivel económico y político internacional, (pues la globalización lo habría arrasado) parece que la fuerza simbólica del Estado-Nación, en este tipo de situaciones traumáticas, se hace presente (al menos en el imaginario colectivo).

En Uruguay existen algunos mitos que están instalados en el "imaginario social" (Perelli; Rial, 1986). Estos mitos fueron aniquilados por la dictadura cívicomilitar, la evidencia de los crímenes cometidos por el propio Estado y sus agentes niegan dichos mitos y de alguna manera se rompe lo que el Uruguay "es".

Hay que mencionar y recordar el acto por el "Nunca Más" llevado adelante en el primer gobierno del Frente Amplio encabezado por Tabaré Vázquez el día 19 de junio de 2007, donde se establecía el Nunca Más: "hermano contra hermano"; "uruguayo contra uruguayo".

La legitimidad de este mensaje fue cuestionado por distintas organizaciones sociales y especialistas referidos a la temática de la historia reciente. Sin embargo el discurso y el mensaje, que quedó circulando en el imaginario colectivo fueron confusos. El impulso del gobierno fue contradictorio, la señal no fue clara y la confusión estaba presente -nos parece- en el mismo discurso, pues luego de desarrollar este primer punto, desarrolla el segundo que explicitaba el estudio de los cinco tomos que Presidencia encomendó a los investigadores José Pedro Barrán; Gerardo Caetano y Álvaro Rico (mencionado líneas arriba).

En este trabajo coordinado por estos tres investigadores queda demostrado fehacientemente el terrorismo de estado y los crímenes de lesa humanidad, en donde se cometieron todo tipo de crímenes. En el punto anterior había pedido, había intentado convencer a todos los integrantes de la nación "para avanzar en la reconciliación, en el reencuentro entre todos los uruguayos" y para que "aquellos terribles años que tanto hirieron y dividieron a la sociedad uruguaya" quedaran atrás ${ }^{14}$.

Parece válido preguntarnos: ¿se utilizó la Investigación Histórica políticamente para decir: el Estado investigó, ya sabemos lo sucedido y ahora para

\footnotetext{
${ }^{14}$ No es menor tener presente que este acto fue impulsado por un gobierno que tenía un gran apoyo en la opinión pública. Lo mismo sucedía con quien estaba al frente del gobierno. Con esto intentamos decir que si el mensaje de cualquier gobierno es potente y por tanto "cala hondo" en el imaginario colectivo, éste mensaje fue más profundo aun, nos parece.
} 


\section{Héctor Altamirano}

continuar adelante con la historia debemos reconciliarnos como uruguayos? ${ }^{15}$

Como dice Rilla: "la historia ha sido usada para abastecer las ideas de nación y revolución, fundar o refundar una política exterior, justificar una guerra, resolver una cuenta pendiente con el pasado, afirmar o debilitar un liderazgo político" (Rilla, 2008: 56). Y el anterior puede ser un ejemplo de este uso.

En todos los países en los cuales ocurrieron sucesos traumáticos ${ }^{16}$, en donde los crímenes fueron realizados de forma sistemática por agentes del Estado, en donde las torturas y las violaciones a los derechos humanos fueron moneda corriente, existe esta problemática o al menos, existen diferentes posiciones y visiones, pues como afirma Traverso los debates que se dan en torno a estos sucesos "superan largamente las fronteras de la investigación histórica" (Traverso, 2007: 78) y así se producen "memorias "fuertes" y memorias “débiles" (Traverso, 2007: 86-88).

\section{Subjetividad y olvidos de la historia reciente}

Existen variados autores que toman el tema de la subjetividad en la historia y como ella no es un impedimento para afirmar que se pueda realizar un trabajo sistemático y documentado, en definitiva con rigor científico.

Si lo que pretendemos es presentar alguno de los problemas que se plantean a la hora de estudiar el pasado reciente, debemos, por pequeña que sea, hacer un alto en este punto.

Bermejo plantea que la "introducción de la subjetividad en historia fue posible por la presencia de la Escuela de los Annales", ya que tomaba como eje el presente del historiador. Dicha Escuela afirma que el historiador trabaja, e investiga, pensando en su presente y así es que interroga a los documentos. Según esta Escuela "el historiador no es un frío analista del pasado, sino un apasionado estudioso del presente, que busca en el pasado las redes del mismo". Siguiendo esta idea-clave es que pensamos que los historiadores nacionales que estudian el período dictatorial parten desde intereses e inquietudes del presente.

En este sentido y para ir terminando este breve trabajo, podemos decir que hoy existen varios grupos políticos que no tienen ningún tipo de interés en conocer lo que pasó en aquellos años, no les interesa indagar sobre esos momentos de la historia reciente, o intentan "suavizar" el pasado ${ }^{17}$ para centrarse en el presente y

\footnotetext{
15 Recordemos las palabras de Frega ya citadas: "Es indudable que todo discurso histórico, aún aquél construido con el mayor rigor metodológico y la mayor diversidad de fuentes disponibles en el momento de su elaboración es susceptible de usos políticos" (Frega, 2008: 23).

16 Como plantea Rilla el Holocausto, los genocidios armenios y ucranianos, los procesos de desnazificación y desfascistización, el poscomunismo y las dictaduras de latinoamericanas, hasta el día de hoy están vivos en la literatura y en el debate político. (Rilla, 2008: 54-55).

17 No nos detendremos en los grupos que tradicionalmente se han negado a estudiar y revisar el pasado reciente, especialmente las Fuerzas Armadas, pues merecería un trabajo y una investigación específica.
} 


\section{Una historia peligrosa: la Historia Reciente bajo sospecha}

lograr los objetivos político-partidarios inmediatos, pues la necesidad es la de operar en este momento.

Entre los partidos/movimientos que componen el actual gobierno del Frente Amplio, existen algunos que se resisten fervientemente (otros lo hacen de forma moderada) hasta el día de hoy a analizar los temas de lo sucedido desde el año 1968 hasta el día de hoy. Y esto se debe a que, como dice Yaffé (2004), nadie quiere asumir el papel que desarrolló en aquél momento.

El mismo autor afirma que

los documentos de balance del período 1968-1973 que circularon en la izquierda política y en el movimiento sindical y estudiantil entre 1983-1989 evidencian las dificultades de la izquierda uruguaya para enfrentar y asimilar su pasado inmediato. Las posiciones variaron del hipercriticismo de los tupamaros a la reticencia de los comunistas. (Yaffé, 2004: 190)

Y continúa diciendo el mismo autor: "el MLN concentró su energía en procesar una "autocrítica" (Yaffé, 2004: 190). Pero esta "autocrítica" nunca se hizo pública como tendencia política organizada, nunca hubo un claro y profundo pronunciamiento al respecto. Más bien hay variadas posiciones y matices al respecto (aunque los dirigentes o integrantes más reconocidos suelen comulgar con la teoría de los dos demonios ${ }^{18}$ ).

El Partido Comunista tampoco dejó constancia de haber realizado algún balance autocrítico al respecto de este período histórico. Lo que peso aquí fue

seguramente [...] el hecho de que el PC era blanco de la mayoría de las críticas provenientes de otros grupos de la izquierda a la hora de efectuar el "balance" del período 1968-1973. La táctica política y sindical seguida por los comunistas en esa coyuntura, fue objeto de los más fuertes cuestionamientos de parte de casi todo el resto de la izquierda que la caracterizaba cuando menos como "reformista" (Yaffé, 2004: 190).

Y termina diciendo este investigador que "de hecho, el tema nunca llegó a instalarse oficialmente en el Frente Amplio" (Yaffé, 2004: 191).

\footnotetext{
18 Vale la pena reiterar un fragmento del discurso del presidente José Mujica del día 18-5-2011 es un claro ejemplo. En ese discurso se puede leer lo siguiente: "no podemos trasladarle a las nuevas generaciones de militares las frustraciones de la nuestra, porque necesitamos un país convivible, un país que antes que nada y por encima de sus diferencias tenga el coraje de poner adelante el "nosotros"; luego agregaba que debemos "cultivar una tolerancia superior entre nosotros" y todo esto lo dice no como presidente sino "como viejo que se puso un arma al cinto". Otro de los que comulgan y comparten esta visión es el Ministro Eleuterio Fernández Huidobro que en el mes de diciembre de 2014 hizo pública su reticencia a un informe del Servicio Paz y Justicia, en donde se lo señala como uno de los responsables de entorpecer los intentos de avances sobre la verdad y la justicia acontecidos durante la dictadura.
} 


\section{Héctor Altamirano}

\section{Conclusiones}

A lo largo del trabajo se ha intentado reflexionar sobre la relación de la entre la ciencia, la política y la sociedad, especialmente en el área de las ciencias sociales. Aunque se intentó demostrar que no es exclusivo de estas ciencias las "dificultades" o las tensiones que se generan, pues los científicos viven y están inmersos en una sociedad y ellos no pueden aislarse en una torre de marfil, siempre viven y sienten lo que sucede en su sociedad.

Específicamente sobre una actividad científica como la Historia se generan diversos problemas que a la hora de estudiar el pasado reciente se pueden evidenciar. Contrariamente a lo afirmado por Tabaré Vázquez en su discurso del 4 de junio de 2006 que afirmaba: "No existe la historia oficial (...) existe la historia a secas", rastreando, acercándonos apenas a este tema, nos atrevemos a afirmar que para la historia nacional, para la historia que crea el sentimiento de unidad, de unión entre todos los uruguayos este período histórico es un gran problema.

Es un gran problema -parece- no para los profesionales e investigadores que cultivan la temática, sino en otros actores que juegan en este campo un papel fundamental: los políticos profesionales que están al frente del gobierno, los cuales están en torno del Estado. Recordemos que "la nación requiere de símbolos míticos de unidad para su eterna permanencia" (Piazza, 2003: 64). No es casual que los discursos citados anteriormente -el de T. Vázquez y el de J. Mujica- fueron pronunciados en fechas patrias (o hacían referencia a ellas), fechas que conmemoraban la figura del prócer; en ambos discursos se hace referencia al padre de la patria, al héroe que encarnó las ansias de todo un pueblo de ser libre: se hacer referencia al símbolo de unidad nacional, al mito fundante.

A partir de ese momento es que se instaura -creemos- un problema para los cultores de esta temática, allí tienen que disputar la legitimidad del discurso. Hasta el momento el discurso de los políticos profesionales, el discurso oficial, se impone en la sociedad y es por ello que se generan diferencias entre los investigadores y los políticos (caso Demasi y el Partido Nacional, es el más notorio).

¿Cómo encarar un tema que puede entorpecer al gobierno y a los distintos grupos que lo integran o integrarán?; ¿es un problema pura y exclusivamente de los investigadores o implica a toda la sociedad?; ¿cómo hacer para construir un discurso que sea contra hegemónico y que brinde una mirada no controlada por el Estado?

Este parece ser el problema más acuciante que debe enfrentar aquél que quiera escribir y reflexionar sobre la historia reciente en el Uruguay y por eso estará bajo sospecha.

\section{Bibliografía}

ARÓSTEGUI, J. La investigación histórica: teoría y método. Crítica. Barcelona. 2001.

BARRÁN, J.P. Los cuestionamientos y desafíos de la historia reciente, en: RICO, A 


\section{Una historia peligrosa: la Historia Reciente bajo sospecha}

(Comp). Historia reciente. Historia en discusión, CEIU-MEC-PNUD, Montevideo, 2008, p. 11-13.

BOURDIEU, P. Intelectuales, política y poder, Eudeba, Bs. As. 2009.

CAETANO, G. "Aportes para la construcción de un "momento de verdad" y una "memoria ejemplar": la tardía investigación sobre el destino de los "detenidosdesaparecidos" en el Uruguay. Los archivos de la dictadura", en: RICO, A (Comp). Historia reciente. Historia en discusión, CEIU-MEC-PNUD, Montevideo, 2008, p. 163-215.

de GIORGI, A. Sangüinetti. La otra historia del pasado reciente, Fin de Siglo, Montevideo, 2014.

DEMASI, C. “2006: el año de la historia reciente”, en: RICO, A (Comp). Historia reciente. Historia en discusión, CEIU-MEC-PNUD, Montevideo, 2008, p. 31-48.

DEMASI, C. "Un repaso a la teoría de los dos demonios", en: Marchesi, A; Markarian, V; Rico, A; Yaffé, J. (comp.) El presente de la dictadura. Estudios y reflexiones a 30 años del golpe de Estado en Uruguay, Trilce, Montevideo, 2004, pp. 67-74.

FREGA, A. Combates por la "Historia reciente" en Uruguay, en: RICO, A (Comp). Historia reciente. Historia en discusión, CEIU-MEC-PNUD, Montevideo, 2008, p.15-30.

PEREIRA, M. en Brecha. 30-9-2005. p. 3.

PERELLI, C; RIAL, J. De mitos y memorias políticas. EBO, Montevideo, 1986.

PIAZZA, E. "Caminos heroicos y caminos de la nación”, en: Demasi, C y Piazza. E (Comp). Los Héroes fundadores. Perspectivas desde el Siglo XXI, CEIU-FHCE, Montevideo, 2003, pp. 55-71.

RICO, A (Comp). Historia reciente. Historia en discusión, CEIU-MEC-PNUD, Montevideo, 2008.

RICO, A. (coord.), Investigación Histórica sobre Detenidos-Desaparecidos, en cumplimiento del Artículo $4^{\circ}$ de la Ley 15.848. Tomo I. "Contexto Represivo. Testimonios."

RICO, A. "Reflexiones sobre algunas características y problemas del estudio de la historia reciente del Uruguay (1968-1987)", en: Revista Hoy es Historia, № 34, 1989. pp. 45-50.

RILLA, J. La actualidad del pasado. Usos de la historia en la política de partidos del Uruguay (1942.1972), Debate, Montevideo, 2008.

TRAVERSO, E. "Historia y memoria. Notas sobre un debate", en: Franco, M. y Levin, F. (comp.) Historia reciente. Perspectivas y desafíos para un campo en construcción. Buenos Aires, Paidós, 2007, pp. 67-96.

YAFFÉ, J. Al centro y adentro. La renovación de la izquierda y el triunfo del Frente 


\section{Héctor Altamirano}

Amplio en Uruguay, Linardi y Risso, Montevideo, 2005.

YAFFÉ, J. "Memoria y olvidos en relación con la izquierda y el pasado reciente" en: A. Marchesi, V. Markarian, Á. Rico; Yaffé, J (comp.) El presente de la dictadura. Estudios y reflexiones a 30 años del golpe de Estado en Uruguay, Trilce, Montevideo, 2004, pp. 184-198. 